\title{
Development and Performance Evaluation of Sucker Cutting Tool for Banana
}

\author{
P.R. Sabale ${ }^{*}$, S.B. Patil and J.S. Ghatge \\ Dr. DYP CAET, Talsande, Kolhapur, India \\ *Corresponding author
}

\begin{tabular}{|l|}
\hline Ke y w or d s \\
$\begin{array}{l}\text { Introduction, methods } \\
\text { of de-suckering, } \\
\text { Sucker cutting tool, } \\
\text { Working capacity }\end{array}$ \\
\hline Article Info \\
\hline $\begin{array}{l}\text { Accepted: } \\
\text { 12 April } 2018 \\
\text { Available Online: } \\
\text { 10 May } 2018\end{array}$ \\
\hline
\end{tabular}

\section{A B S T R A C T}

Banana (Musa sp.) is the second most important fruit crop in India next to mango. Its year round availability, affordability, varietal range, taste, and nutritive medicinal value makes it the favorite fruit among all classes of people. Suckers are the unwanted plants that grow around the mother plant and greatly affect the mother plant growth, taking essential nutrients from them. It also affects the banana bunch growth hence affecting the physical properties and their characteristics which ultimately affects the quality. Therefore these suckers are required to be removed in order to have a healthy growth of the banana plant including banana bunches and combs. De-suckering is the practice of removing unwanted suckers that grows around the mother banana plant. As the plant grows, a number of suckers grow from the rhizome of the mother plant. The average number of suckers that grows around is usually 3-6. These suckers compete with the main plant for its food and nutrients. Thus, controlling these suckers is a must to maintain normal bunch weight and quality. De-suckering is done manually with the help of sickle which is inefficient, time consuming, inflict substantial loss to stem of banana, as well as cause musculoskeletal stress on farm workers. Therefore it is necessary to develop an ergonomically designed banana de-suckering tool which can reduce the physical discomfort during cutting operation without affecting the speed of operation, also it should take less time and energy for the same. The performance evaluation of sucker cutting tool was done by using the two methods i.e. developed method and traditional method based on parameters such as sucker diameter, sucker height, number of sucker/plant, moisture content. In traditional method, sucker was removed using sickle. The maximum working capacity ranges obtained from traditional method was $16 \mathrm{plant} / \mathrm{min}$ while $29 \mathrm{plant} / \mathrm{min}$ was observed with the help of developed tool. Operations with Developed tool resulted in less fatigue and did not cause any unnecessary scratches and damage to the main plant. Also frequent sharpening was not required for the blade of developed tool as in case of sickle which resulted in less time loss during the working period, increasing the productivity of the operation. The advantages of this "Developed tool" are that it is easy to use and does not require highly skilled labor. Finally, "Developed tool" could serve as tool to the banana farmers. This tool is designed to operate properly, easy to use and easy to maintain. 


\section{Introduction}

Banana (Musa sp.) is the second most important fruit crop in India next to mango. Its year round availability, affordability, varietal range, taste, and nutritive medicinal value makes it the favorite fruit among all classes of people.

It has also good export potential. Banana is rich source of carbohydrate and is rich in vitamins particularly vitamin B. It is also good source of potassium, phosphorus, calcium and magnesium. The fruit is easy to digest, free from fat and cholesterol. Banana power is used as the first baby food. It helps in reducing risk of heart diseases when used regularly and is recommended for patients suffering from high blood pressure, arthritis, ulcer, gastroenteritis and kidney disorders.

Processed products, such as chips, banana puree, jam, jelly, juice, wine and halva can be made from the fruit. The tender stem, which bears the inflorescence is extracted by removing the leaf sheaths of the harvested pseudo stem and used as vegetable. Plantains or cooking bananas are rich in starch and have a chemical composition similar to that of potato.

Banana fiber is used make items like bags, pots and wall hanger. Rope and good quality paper can be prepared from banana waste. Banana leaves are used as healthy and hygienic eating plates.

\section{Area, production and productivity}

Banana and plantains are grown in about 120 countries. Total annual world production is estimated at 86 million tons of fruits. India leads the world in banana production with an annual output of about 14.2 million tones. Other leading producers are Brazil, Indonesia, Cost Arica, Mexico, Thailand and Colombia.
In India banana ranks first in production and third in area among fruit crops. It accounts for $13 \%$ of the total area and $33 \%$ of the production of fruits. Production in highest in Maharashtra (3924.1 thousand tones) followed by Tamil Nadu (3543.8 thousand tons).

Within India, Maharashtra has the highest productivity of 37 metric tons/ha. against national average of 30.5 tons/ha. The other major banana producing states are Karnataka, Gujarat, Andhra Pradesh and Assam. (National Horticulture Board 2014)

The area, production and productivity of banana fruit grown in the country are given in Table 1.

\section{Importance of de-suckering}

De-suckering is the practice of removing unwanted suckers. As the plant grows, a number of suckers also grow from the rhizome. These suckers compete with the main plant for its food and nutrients. Thus, controlling these suckers is a must to maintain normal bunch weight and quality.

\section{Method of de-suckering}

De-suckering should start from two months after planting of banana. The side suckers should be removed by cutting at their base. Hereafter, a few drops of kerosene should be poured inside it to arrest further growth. And the process should repeat every 45 days till the plant flowers (Bose, 2001).

There are three main methods used to desucker bananas are a suckering bar basically a long handled shovel, which removes sucker from the base of the parent plant; a sharp knife to cut off unwanted suckers that are then injected with kerosene or diesel; direct injection of suckers (Handbook of Subtropical Banana Grower, 2004). 


\section{Importance and justification of study}

As we know the traditional method of desuckering means cutting off unwanted shoots from the stems of the mother banana plant. Use a knife to cut off the stems of the suckers which have grown to about the size of a foot.

When planting on a slope, always leave the suckers which are on the uphill side. Cut off all suckers which are on the north-western side of the banana plant. This is the side where the bunch hangs. After 5 months from planting, select only 1 vigorous sucker to carry the next bunch. (ARC -Institute for Tropical and Subtropical Crops Banana Production).

In the manual de-suckring, these are inefficient and more importantly, time consumable operations and require more labour, inflict substantial loss to steam of banana, as well as cause musculoskeletal stress on farm workers. Therefore it is necessary to develop an ergonomically designed banana de-suckring tool which can reduce the physical discomfort during cutting operation.

\section{Materials and Methods}

The designed machine was comprised of following components.

\section{Cutting blade}

The sucker plant was cut with the help of cutting blade as shown in figure 1 . It is made up of stainless steel. The width of cutting blade is depends on the maximum diameter of sucker plant. Cutting blade is measured by using measuring tape.

There are two angles of positions with cutting blades selected for sucker cutting $\left(0^{\circ}\right.$ and $\left.30^{\circ}\right)$. The dimensions of cutting blade are shown in Table 2.

\section{Extension pipe}

It is also called as telescopic pipe because two numbers of pipes in different diameters were attached to each other to form a telescopic pipe as shown in figure 2. The two locking mechanisms were provided to extend or minimize the length of extension pipe as per requirement of cutting tree. The cutting blade is mounted on the end of extension pipe. It was made up of stainless steel. The different parameters of extension pipe are given in the Table 3.

\section{Handle grip}

The handle length was optimized on the basis of anthropometric dimensions of workers and it's made up of rubber as shown in figure 3. Handle length was optimized based on hand breadth at thumb and hand length. The different parameters of handle grip are given in the Table 4.

\section{Performance evaluation of sucker cutting tool}

\section{Working capacity (ha/hr)}

It is the ratio of number of plants cut per time.

Working capacity $\left(\frac{h a}{h r}\right)=\frac{\text { number of plants cut }}{\text { time }}$

\section{Results and Discussion}

The results of the experiments carried out in different phases are discussed and presented in this chapter under the following headings.

\section{Working capacity}

The performance evaluation of sucker cutting tool was done by using the two methods such as traditional method (Fig. 4) and developed method (Fig. 5). 
Table.1 The area, production and productivity of banana fruit grown in the country

\begin{tabular}{|c|c|c|c|}
\hline Year & $\begin{array}{c}\text { Production } \\
\left({ }^{\circ} 000 \text { MT) }\right.\end{array}$ & $\begin{array}{c}\text { Area } \\
(' 000 ~ H a)\end{array}$ & $\begin{array}{c}\text { Productivity } \\
\text { ('000 MT/Ha) }\end{array}$ \\
\hline $\mathbf{2 0 1 6 - 1 7}$ & 29163 & 858 & 34 \\
\hline $\mathbf{2 0 1 5 - 1 6}$ & 29135 & 841 & 35 \\
\hline $\mathbf{2 0 1 4 - 1 5}$ & 30008 & 880 & 34.1 \\
\hline $\mathbf{2 0 1 3 - 1 4}$ & 29724.6 & 802.6 & 37 \\
\hline $\mathbf{2 0 1 2 - 1 3}$ & 26509.1 & 776 & 24.2 \\
\hline
\end{tabular}

Source: National Horticulture Board (2017)

Table.2 Dimensions of cutting blade

\begin{tabular}{|c|l|c|}
\hline Sr. No. & \multicolumn{1}{|c|}{ Particular } & Dimension \\
\hline 1. & Weight $(\mathrm{gm})$ & 65 \\
\hline 2. & Length of cutting edge CS $(\mathrm{mm})$ & 200 \\
\hline 4. & Material & Cast iron \\
\hline 5. & Chord length, CL $(\mathrm{mm})$ & 180 \\
\hline 6. & Blade concavity, C $(\mathrm{mm})$ & 40 \\
\hline
\end{tabular}

Table.3 Dimensions of extension pipe

\begin{tabular}{|c|l|c|c|}
\hline Sr. No. & \multicolumn{1}{|c|}{ Particular } & Pipe 1 & Pipe 2 \\
\hline 1. & Diameter $(\mathrm{mm})$ & 25 & 20 \\
\hline 2. & Length $(\mathrm{mm})$ & 1070 & 300 \\
\hline 4. & Material & Stainless steel & Stainless steel \\
\hline 5. & Thickness $(\mathrm{mm})$ & 1 & 3 \\
\hline 6. & Weight $(\mathrm{gm})$ & 280 & 185 \\
\hline
\end{tabular}

Table.4 Dimensions of handle grip

\begin{tabular}{|c|l|c|}
\hline Sr. No. & \multicolumn{1}{|c|}{ Particular } & Dimension \\
\hline 1. & Diameter $(\mathrm{mm})$ & 30 \\
\hline 2. & Length $(\mathrm{mm})$ & 120 \\
\hline 4. & Material & rubber \\
\hline 5. & Thickness $(\mathrm{mm})$ & 5 \\
\hline 6. & Weight $(\mathrm{gm})$ & 280 \\
\hline
\end{tabular}


Table.5 Field performance of developed method and traditional method

Time (1 Min)

\begin{tabular}{|c|}
\hline $\mathbf{T}_{1}$ \\
\hline $\mathbf{T}_{2}$ \\
\hline $\mathbf{T}_{3}$ \\
\hline $\mathbf{T}_{4}$ \\
\hline $\mathbf{T}_{5}$ \\
\hline $\mathbf{T}_{6}$ \\
\hline $\mathbf{T}_{7}$ \\
\hline $\mathbf{T}_{8}$ \\
\hline $\mathbf{T}_{9}$ \\
\hline $\mathbf{T}_{10}$ \\
\hline $\mathbf{A v g}$. \\
\hline
\end{tabular}

\section{No. of Plant cut}

\begin{tabular}{|c|c|}
\hline Traditional Method & Developed Method \\
\hline 10 & 28 \\
\hline 12 & 23 \\
\hline 11 & 29 \\
\hline 12 & 26 \\
\hline 13 & 23 \\
\hline 14 & 27 \\
\hline 12 & 22 \\
\hline 13 & 25 \\
\hline 16 & 29 \\
\hline 11 & 26 \\
\hline 13 & $\mathbf{2 6}$ \\
\hline
\end{tabular}

Fig.1 Cutting blade
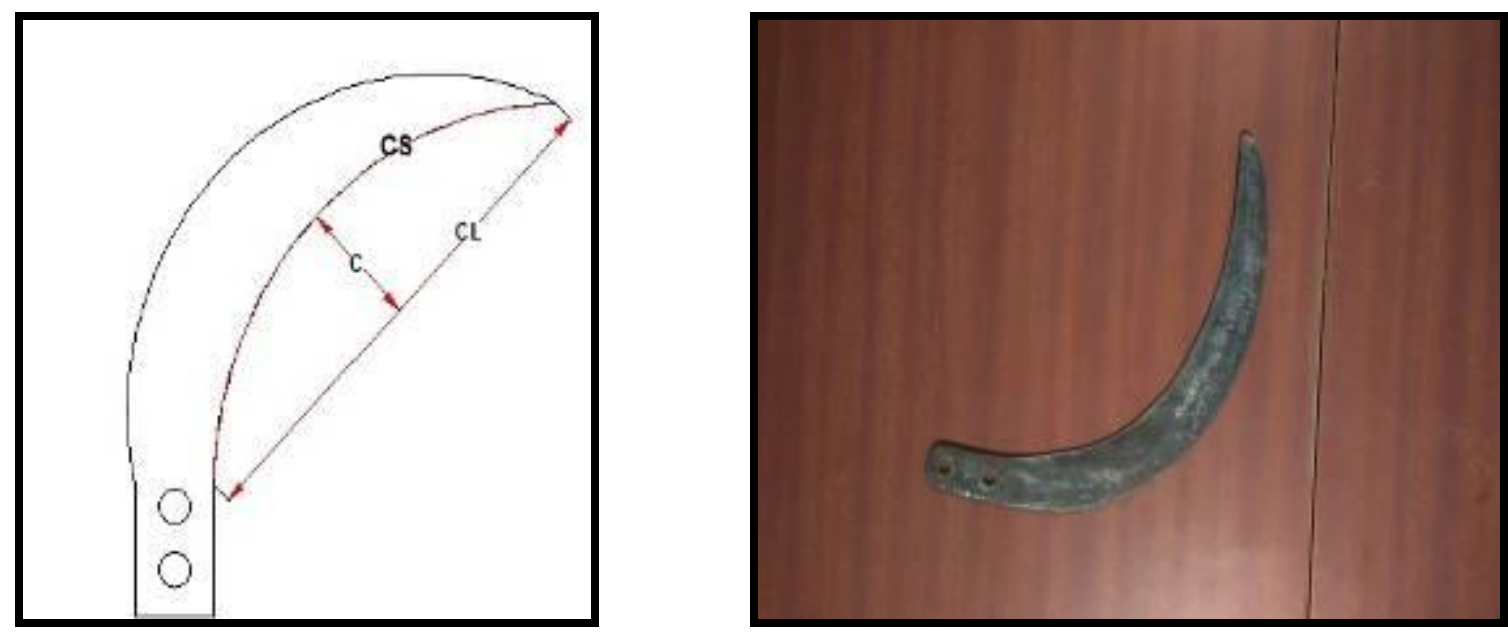

Fig.2 Extension pipe

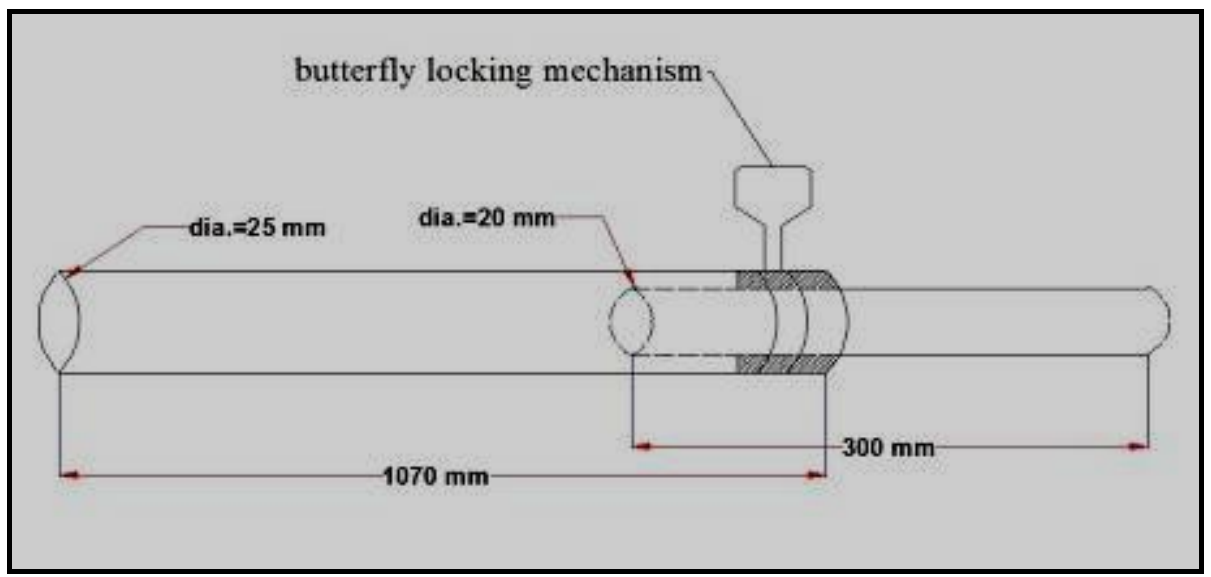




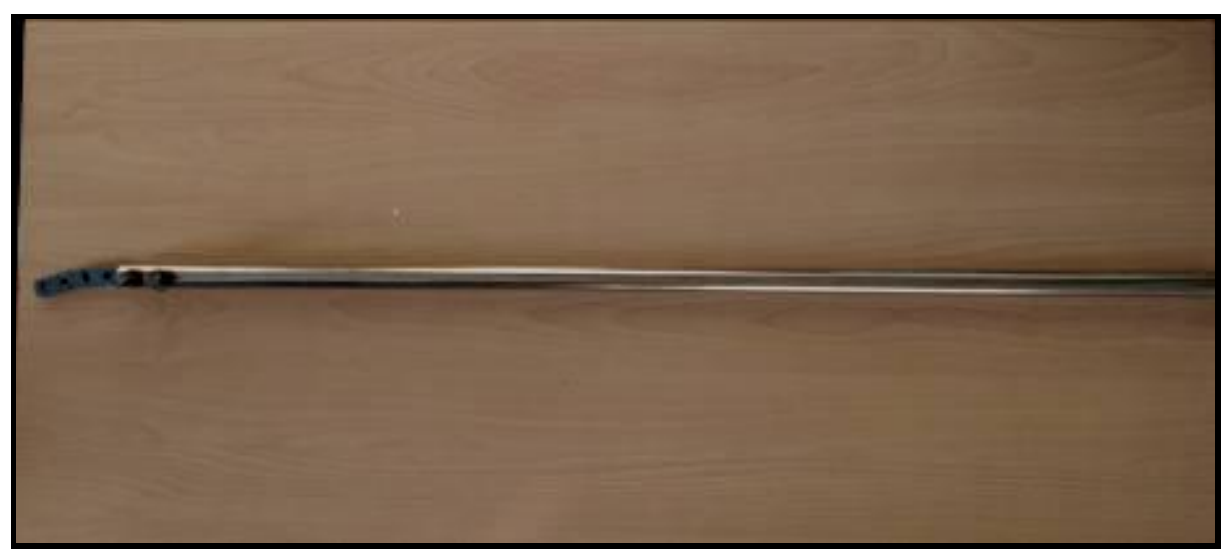

Fig.3 Handle grip

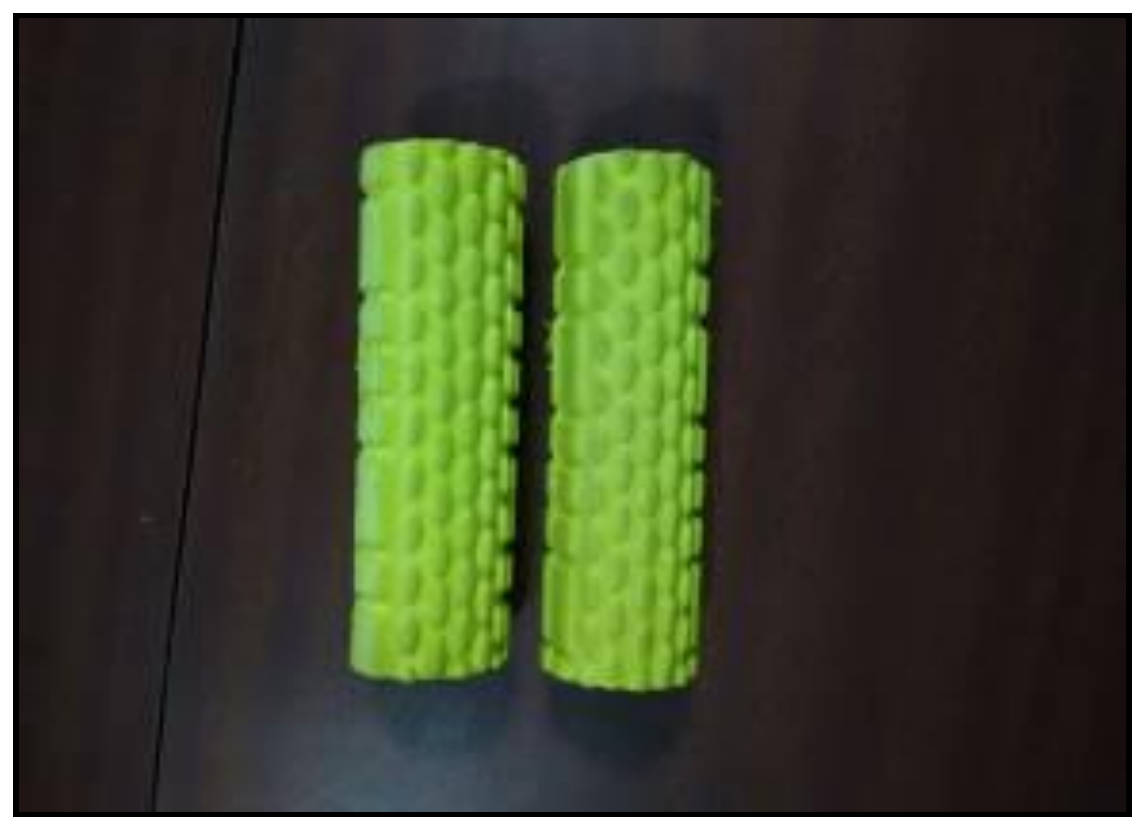

Fig.4 Traditional method

Fig.5 Developed method

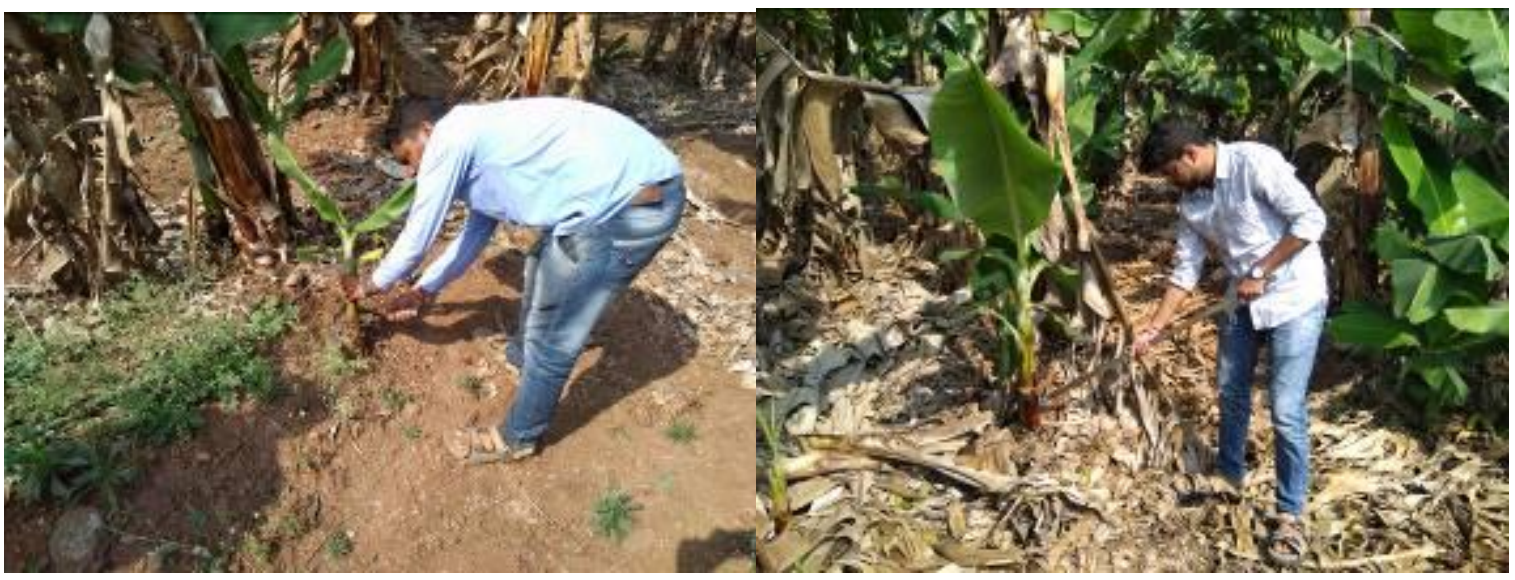


Fig.6 Average traditional and developed methods

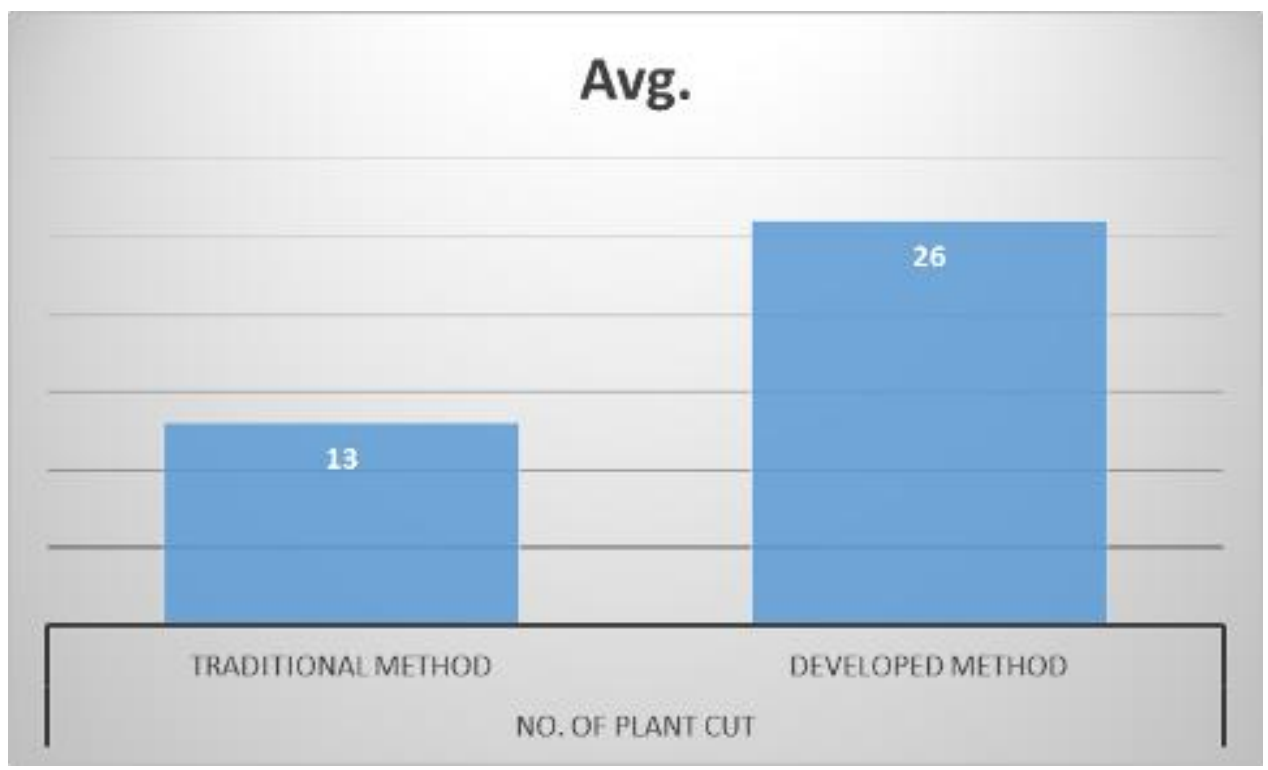

In the traditional method sucker cut is done by using sickle. The field performance of developed method and traditional method was done in the different farm with taken 10 readings per one minute of time as shown in Table 5.

The output capacity or working capacity of sucker cutting tool is mostly affected by the number of sucker present near the mother tree. Output obtained during cutting operation is presented in Table 5. The maximum number of pants cut per unit time was 16 plants/min and 29 plants/min for cutting sucker of traditional and developed technique, respectively.

Therefore, the figure 6 shows the working capacity of developed method was doubled as compare to traditional method. The time required for cutting of sucker tree was minimum due to rapid cutting action of developed tool as compared to traditional method.

Though the cutting efficiency of traditional method is low as compare to development method because the time required for cutting is more and an ergonomically consideration, the cutting action was not done at continuous period cause musculoskeletal stress on farm workers. In traditional method, during cutting action of sucker the farm workers bend at certain angle (Fig. 4) due to lack of ergonomically design hence they were not done to continuous operation on the field. But in developed method, the cutting tool was developed an ergonomically. In the developed tool the extension pipe is provided to extend or minimize the length of tool as per requirement of cutting tree or man height (Fig. 5) which can reduce the physical discomfort during cutting operation. Therefore the developed method was better performance as well as good ergonomically designed than the traditional method.

This chapter deals with the overall summary of the results obtained during entire period of the research work. The advantages of this "Developed tool" are that it is easy to use and does not require highly skilled labor. This tool also does not harmful to worker. Another advantage of this tool is it can sweep or cut faster than the sickle. Generally, to create a project, it requires high skills and creativity 
finally, "Developed tool" could serve as tool to the banana farmers. This tool is designed to operate properly, easy to use and easy to maintain.

The developed tool required less time as compared to traditional method.

The developed tool did not harmful to worker.

The developed tool had high working efficiency as compared to traditional method.

\section{References}

Adeyemi O. S., and Oladiji A. T. (2009). Compositional changes in banana (Musa ssp.) fruits during ripening. African Journal of Biotechnology, 8(5).

Bhende S.S and Kurien, 2015. Sucker production in banana. Journal of Tropical Agriculture, 53(2): 97-106, 2015.
Bose, T. K., Mithra, S.K., Sanyal, D. (1996) Fruits: Tropical and Sub-Tropical, Naya Udyog Publications, Calcutta.

Daniells, J. W., and O'Farrell, P. J. (1987). Effect of cutting height of the parent pseudostem on yield and time of production of the following sucker in banana. Scientia horticulturae, 31(1-2), 89-94.

Mathanker, S.K, Tony E. Grift, T.E. and Hansen, A.C. (2015) Effect of blade oblique angle and cutting speed on cutting energy for energy cane stems. Biosystems Engineering, 133, 64-70. DOI: 10.1016/j.biosystemseng.2015.03. 003

Odeke, M., Rubaihayo, P.R and Osiru. D.S.O. 1999. African Crop Science Journal, Vol. 7. No. 4, pp. 349-353,

Seif, G., Fatih, M.M and Fatima, A.R.A. 2014. International Journal of Science, Environment and Technology, Vol. 3, No 1, 2014, 357 - 364

\section{How to cite this article:}

Sabale, P.R., S.B. Patil and Ghatge, J.S. 2018. Development and Performance Evaluation of Sucker Cutting Tool for Banana. Int.J.Curr.Microbiol.App.Sci. 7(05): 1655-1662.

doi: https://doi.org/10.20546/ijcmas.2018.705.196 